\title{
Adolescent risk-taking as a function of prenatal cocaine exposure and biological sex
}

\author{
Jedediah W.P. Allen ${ }^{\mathrm{a}, *}$, David S. Bennett ${ }^{\mathrm{b}}$, Dennis P. Carmody ${ }^{\mathrm{c}}$, Yiping Wang ${ }^{\mathrm{d}}$, Michael Lewis ${ }^{\mathrm{d}, *}$ \\ a Department of Psychology, Bilkent University, Ankara, Turkey \\ ${ }^{\mathrm{b}}$ Department of Psychiatry, Drexel University College of Medicine, Philadelphia, PA, USA \\ ' Rutgers University School of Nursing, Newark, NJ, USA \\ d Institute for the Study of Child Development, Department of Pediatrics, Rutgers Robert Wood Johnson Medical School, New Brunswick, NJ, USA
}

\section{A R T I C L E I N F O}

\section{Article history:}

Received 18 February 2013

Received in revised form 27 November 2013

Accepted 6 December 2013

Available online 12 December 2013

\section{Keywords:}

Risk-taking

Adolescence

Prenatal cocaine exposure

Biological sex

\begin{abstract}
A B S T R A C T
Objective: To examine the effects of prenatal cocaine exposure and biological sex on adolescent risk-taking while controlling for early environmental risk.

Methods: Adolescents $(\mathrm{n}=114$, mean age $=16$ ) were grouped according to high and low risk-taking propensity as measured by the Balloon Analogue Risk Task (BART). Prenatal cocaine exposure was assessed at birth, while environmental risk was assessed at three points during early childhood.

Results: A binary regression analysis indicated that males were 3.5 times more likely than females to be high risk-takers. Biological sex and prenatal cocaine exposure interacted such that exposed males were most likely to be high risk-takers while exposed females were the least likely to be high risk-takers. This pattern held after controlling for prenatal alcohol exposure and early environmental risk. Early environmental risk did not predict adolescent risk-taking.

Conclusions: These findings complement and extend earlier research demonstrating that prenatal cocaine exposure interacts with biological sex in domains related to inhibitory control, emotion regulation, antisocial behavior, and health risk behaviors during preadolescence.
\end{abstract}

(c) 2013 Elsevier Inc. All rights reserved.

\section{Introduction}

Previous research on the effects of prenatal cocaine exposure (PCE) has demonstrated that there are both cognitive and regulatory impairments during childhood that are associated with cocaine exposure (Ackerman et al., 2010). Further, these impairments often manifest most strongly when moderated by biological sex and, in some cases, by environmental risk (Lewis and Kestler, 2011). In particular, PCE males who are also from high risk environments tend to show increased impairments for sustained attention, inhibitory control, emotion regulation, aggression, and other antisocial behavior problems throughout childhood (Bandstra et al., 2001; Delaney-Black et al., 2004; Dennis et al., 2006; Kestler et al., 2011; Richardson et al., 2009). Though more limited, research on preadolescence seems to indicate a continuation of the cognitive and regulatory impairments found at earlier ages (Bada et al., 2011; Bennett et al., 2007, 2013; Bridgett and Mayes, 2011; Carmody et al., 2011). With the onset of adolescence comes an

\footnotetext{
is Conflict of interest and sources of funding: None declared. This study was supported by Grant DA07109 to Michael Lewis, David S. Bennett, \& Dennis, P. Carmody from the National Institute on Drug Abuse.

* Corresponding authors at: 89 French Street, New Brunswick, NJ 08901, USA. Tel.: +1 732235 7700; fax: +1732 2356189 .

E-mail addresses: jedediahwpallen@gmail.com (J.W.P. Allen), lewis@rwjms.rutgers.edu (M. Lewis).
}

increase in particular types of risk-taking behavior (Steinberg, 2004), making this an important developmental period in which to examine the effects of PCE. The central question being asked by the current study is whether prenatal exposure to cocaine can predict adolescent risk-taking, especially for males, while controlling for the effects of early environmental risk.

Liu and Lester (2011) have proposed a developmental model for how PCE impacts dopamine and hypothalamic-pituitary-adrenal (HPA) systems during early brain development. They discuss some of the short-term consequences of disruption to these systems but argue that there are also long-term effects that may manifest after "prolonged incubation". These long-term effects are a consequence of both adaptations of the brain to the early prenatal cocaine environment as well as interference to the extensive brain maturational processes that take place during adolescence. In particular, PCE may affect the prefrontal cortex (PFC) as indicated by imaging studies showing children with PCE to exhibit differences in activation of the PFC during a response inhibition task as well as differences in the microstructure of frontal white matter (Sheinkopf et al., 2009; Warner et al., 2006). A more recent study of young adolescents found that, relative to non-exposed peers, the PCE group had lower fractional anisotropy in the right arcuate fasciculus (axons connecting the Broca's area and Wernicke's area) and the structural abnormalities were related to executive functioning (Lebel et al., 2013). Such differences may negatively impact the 
cognitive processes of regulation, attention, and inhibition. In turn, these cognitive and regulatory abilities may be essential for proper impulse control, rule compliance, and decision-making that involve the potential for risk-taking.

Adolescence presents children with new realms of potential social interactions as well as expanded independence. Consequently, the opportunity and prevalence of risk-taking behaviors increase during adolescence (Jessor, 1991; Steinberg, 2004) and may set the stage for maladaptive behavior in adulthood. Risk-taking behaviors are those that are defined by their potential for harm as well as reward (Leigh, 1999). Research focused on risk-taking in adolescents has often used self-report measures of the frequency of prior health risk behaviors (CDC, 2011). This raises two issues: first, the prevalence of health risk behaviors does not provide researchers with a person-level variable for how to understand the propensity of different groups to engage in risk-taking. That is, measures of prior risk-taking behavior are not optimal for efforts aimed at preventing those behaviors in the first place. Second, although other measures may capture aspects of personality that are related to risk-taking (e.g., sensation seeking, impulsivity, etc.), they tend also to rely on subjective reporting (Lejuez et al., 2002).

In an effort to address these limitations, Lejuez et al. (2002) developed the Balloon Analogue Risk Task (BART). The BART is an objective measure of decision-making that captures the harm versus reward dynamic characteristic of risk-taking. Previous research has demonstrated that the BART is reliable both within a single session as well as across administrations (Lejuez et al., 2003a; White et al., 2008). With respect to validity, research has consistently demonstrated that performance on the BART is related to real-world risk-taking behavior from a variety of domains-substance use, health and safety, and delinquency (Aklin et al., 2005; Fernie et al., 2010; Lejuez et al., 2003a,b). Finally, the reliability and validity of the task have also been demonstrated for innercity adolescents (Lejuez et al., 2007).

Previous research has demonstrated that PCE is related to poor inhibitory control, impulsivity, and aggression, and factors such as these form the basis of subsequent risk-taking and antisocial behavior more broadly (Bendersky et al., 2006; Bendersky and Lewis, 1998; Bridgett and Mayes, 2011; Campbell et al., 2000; Richardson et al., 2011). There is also a growing body of evidence indicating that males may be more affected by PCE than females and this effect remains robust after controlling for environmental risk variables (Bennett et al., 2013; Delaney-Black et al., 2004; Lewis and Kestler, 2011; Liu and Lester, 2011). Controlling for environmental risk is especially important for research on the effects of PCE because many children with PCE reside in high risk environments (Bendersky et al., 1996; Bendersky et al., 2006). Finally, given the relative lack of adolescent data on PCE and risk-taking behavior and the reliance on self-, caregiver-, and teacher-reports in this literature, the current study explored the relation between PCE and biological sex on risk-taking propensity during adolescence while controlling for early environmental risk. Specifically, we hypothesized that PCE males would show a higher propensity for risk-taking than unexposed males or females from either group.

\section{Methods}

\subsection{Participants}

One hundred and fourteen adolescents completed the BART task during their 16-year laboratory visit as part of a larger longitudinal study examining the developmental effects of prenatal cocaine exposure (Kestler et al., 2011). Mothers were recruited from hospital-based prenatal clinics in low socioeconomic status areas of Philadelphia and Trenton. Children were excluded from the study if they were born before 32 weeks of gestation, required special care or oxygen therapy for more than $24 \mathrm{~h}$, exhibited congenital abnormalities, were exposed to opiates or PCP in utero, or were born to mothers infected with HIV.
Two hundred and fifty eight children participated in the first laboratory visit at 4 months and were invited back for follow-up sessions after that. Of the 114 adolescents who participated in the current study, 56 were male and 58 were female with a mean age of 16.0 years ( $\mathrm{SD}=0.29$ years). The participants were predominantly AfricanAmerican (96\%) and 48 (42\%) were exposed to cocaine. Comparing those who participated at 16 years (current-sample) and those who did not (4-month-sample) there were no significant differences in biological sex (Male current-sample $=50 \%$, Male $_{4 \text {-month-sample }}=50 \% ; p=.96$; missing data $=0 \%$, cocaine exposure $\left(\right.$ Exposed $_{\text {current-sample }}=62 \%$, Exposed $_{4 \text {-month-sample }}=69 \% ; p=.30$; missing data $=0 \%$, neonatal medical risk $\left(\mathrm{M}_{\text {current-sample }}=5.68, \mathrm{SD}=4.16, \mathrm{M}_{4 \text {-month-sample }}=5.40\right.$, $\mathrm{SD}=4.13 ; p=.63 ;$ missing data $=27 \%$, or environmental risk $\left(\mathrm{M}_{\text {current-sample }}=3.58, \mathrm{SD}=1.63, \mathrm{M}_{4 \text {-month-sample }}=3.80, \mathrm{SD}=1.70\right.$; $p=.31$; missing data $=20 \%$ ). Multiple imputation was performed on the data set in order to provide accurate statistical estimates for missing data on alcohol, cigarette, marijuana, and environmental risk variables (Schafer and Graham, 2002) using SPSS Version 21.0 MCMC algorithm. Data were assumed to be missing at random (MAR) conditional on the observed data. Although five imputation datasets are often sufficient to eliminate bias, estimates are more efficient with a larger number of imputations and as such twenty imputations were performed (Rubin, 1987; Schafer and Graham, 2002).

\subsection{Procedure}

The participants came with their parent (typically their mother) and were seen at birth, every 4 months during their first year, and every 6 months thereafter with the exception of the 9.5-year laboratory visit. This schedule allowed for a maximum of 30 visits and children were typically seen within a few weeks of their birthday early in the study extending out to within 3-4 months of their birthday by late adolescence. During their visits, children were assessed on a number of instruments used to measure their emotional, behavioral, and cognitive functioning. At the 16 -year visit, the participants were administered the computer-based Balloon Analogue Risk Task (BART) to assess risk-taking.

\subsection{Measures}

\subsubsection{Predictors of adolescent risk-taking behavior}

2.3.1.1. Prenatal substance exposure. Maternal use of cocaine during pregnancy is consistently associated with the use of alcohol, cigarettes, and marijuana. Accordingly, substance use information was obtained from a semi-structured interview administered to mothers within two weeks of their infant's birth. Questions included information about the frequency and amount of the mother's use of cocaine, alcohol, cigarettes, and marijuana. Almost all of the women who used cocaine (99\%) also acknowledged using alcohol, cigarettes, and/or marijuana during their pregnancy. Children were classified as exposed or unexposed to cocaine on the basis of both neonatal meconium screens and maternal interviews. There were no discrepancies between biological and self-report measures of prenatal cocaine exposure. A maternal report for 16 of the 258 children was missing because mothers were not available for an interview but these children were retained on the basis of their meconium screens. Prior reports from this sample have explored dosage considerations for cocaine exposure; however, in those analyses, the dichotomous measure was better able to predict outcomes (e.g., Bendersky et al., 2006; Bendersky and Lewis, 1999; Bennett et al., 2007, 2008). Accordingly, cocaine was dichotomized into exposed and unexposed groups ( 1 vs. 0 ).

Although research focused on prenatal alcohol exposure can dichotomize that variable for some purposes (Sood et al., 2005), research focused on prenatal cocaine exposure tends to maintain the assumption of a dosage response (Mayes et al., 2003; Richardson 
et al., 2013; Singer et al., 2000). In order to maintain this assumption and reduce skew, the distributions of substance use, the alcohol, cigarette, and marijuana exposures were categorized according to a previously used coding scheme (Bennett et al., 2008, 2013): alcohol $(0=0$ drinks/day, $1=0.01-1.00 /$ day, $2=1.01-2.00 /$ day, $3=2.01-3.00 /$ day, and $4=$ more than 3.00/day); cigarettes $(0=0$ cigarettes/day, $1=0.01-1.00 /$ day, $2=1.01-5.00 /$ day, $3=5.01-10.0 /$ day, and $4=$ more than 10/day); and marijuana $(0=0$ joints/day, $1=0.01-0.50 /$ day, $2=0.51-1.00 /$ day, and $3=$ more than $1.00 /$ day $)$.

2.3.1.2. Environmental risk index. Environmental risk variables were assessed through maternal interviews during each of the nine laboratory visits: 4-months, 1.5-, 2.5-, 4.5-, 7.0-, 8.5-, 10.0-, 11.5-, and 13.0-years. Risk variables were selected on the basis of prior research and each of them has been shown, individually, to be relevant for predicting developmental outcomes (Sameroff et al., 1987a). All variables were standardized and dichotomized into high risk (top 25\%) and low risk (bottom 75\%) groups (Sameroff et al., 1987b). For each variable high risk groups received a value of one and low risk groups zero. The risk variables included: maternal life stress based on the Social Environmental Inventory, maternal social support network size based on the Norbeck Social Support Questionnaire, number of regular caregivers (greater number $=$ higher risk), regularity of the child's schedule and stability of their surroundings based on the Family Chaos Scale (R. Seifer, personal communication), single parenthood ( single parent $=$ higher risk), maternal education, and public assistance (public assistance as main source of income $=$ higher risk).

Given that risk factors tend to cluster in the same individual (Masten et al., 1995) and because any single risk variable generally does not predict outcomes as well as a composite, a cumulative environmental risk index score was calculated for each participant. Composite scores are more stable than using individual measures and they are more powerful in terms of detecting effects (e.g., Burchinal et al., 2000).

Given our further interest in controlling for the effects of early environmental risk, which often co-occurs with prenatal substance exposure (Bendersky et al., 1996), we composited the 4-month, 1.5-year, 2.5-year environmental risk scores into a total early environmental risk score. The reason for this decision was based on both theoretical and statistical grounds. Environmental risk is related to children's early self-regulatory processes (Raver, 2004; Sektnan et al., 2010) and such processes have been shown to predict a broad range of developmental and health related outcomes through adolescence (Hoerger et al., 2011; Mischel et al., 2011). Given that these selfregulatory developments take place during the first five years of life, we restricted our potential environmental risk time points to that period (4-months, 1.5-, 2.5-, \& 4.5-years). Next, the results from a correlation analysis of those first four time points indicated the strongest relations between the first three. Environmental risk at four months was highly correlated with environmental risk at the first two time points $(r>.55 ; p<.001)$ but the magnitude of the correlation dropped substantially at 4.5 years $(r<.28 ; p=.012)$. Therefore, in order not to obscure possible effects on adolescent risk-taking that may stem from early, as opposed to later, environmental risk and in accordance with both theoretical and statistical criteria, we combined the first three environmental risk scores.

\subsubsection{Measure of adolescent risk behavior}

2.3.2.1. Risk-taking. The Balloon Analogue Risk Task (BART) is a computer-based measure designed to assess risk-taking propensity (Lejuez et al., 2002). The task involves pumping up a balloon to earn points that are stored in a temporary bank. When the participants decide, they can stop pumping the balloon and transfer their earnings into a permanent bank; however, if the balloon explodes
Table 1

Correlations among predictors, covariates, and risk-taking.

\begin{tabular}{llllllll}
\hline & 1 & 2 & 3 & 4 & 5 & 6 & 7 \\
\hline 1. Risk-taking & - & & & & & & \\
2. Biological sex & $.25^{* *}$ & - & & & & & \\
3. Prenatal cocaine exposure & .06 & -.02 & - & & & & \\
4. Early environmental risk & -.03 & -.06 & .06 & - & & & \\
5. Prenatal alcohol exposure & $.20^{*}$ & .10 & $.70^{* * *}$ & .00 & - & & \\
6. Prenatal cigarette exposure & .11 & -.03 & $.60^{* * *}$ & .15 & $.44^{* *}$ & - & \\
7. Prenatal marijuana exposure & .04 & -.02 & $.46^{* * *}$ & .00 & $.26^{*}$ & $.23^{*}$ & -
\end{tabular}

Note. Correlations are Pearson correlations with the exception of those involving dichotomous variables (i.e., risk-taking, biological sex, and prenatal cocaine exposure), which are Spearman correlations.

${ }^{*} p<.05,{ }^{* *} p<.01,{ }^{* * *} p<.001$.

before the points are transferred, they lose whatever earnings were in the temporary bank. A new balloon appears after either an explosion or a transfer for a total of 30 balloons. Balloon explosions were predetermined and could happen after as few as one pump or as many as 128 pumps. The average balloon explosion point was 64 pumps. Based on the instructions of Lejuez et al. (2002) the participants were not given any specific probability information. Instead, they were instructed, "The bigger you pump up the balloon, the more points you will build up. But if the balloon pops, then you lose the points built up on that balloon". Consistent with prior research using the BART (Aklin et al., 2005; Fernie et al., 2010; Lejuez et al., 2003a,b), our dependent measure was the adjusted average number of pumps (i.e., average number of pumps on balloons that did not explode). Excluding trials in which balloons explode is preferred because those trials necessarily constrain betweenparticipant variability for the unadjusted measure (Lejuez et al., 2002). These scores were then dichotomized into high risk (top 25\%) and low risk (bottom 75\%) groups (Crowley et al., 2009; Sameroff et al., 1987b).

\section{Results}

\subsection{Bivariate correlations}

Table 1 presents the correlations between study variables. Male sex and prenatal exposure to alcohol were associated with high risktaking. ${ }^{1}$ PCE, early environmental risk, prenatal cigarette exposure, and prenatal marijuana exposure were unrelated to risk-taking. Prenatal alcohol, cigarette, and marijuana exposure were evaluated in order to determine whether to include them as covariates in the regression analyses. Neither cigarette exposure nor marijuana exposure had $p$ values less than .20 and were thus not included as covariates in predicting risk-taking. Although early environmental risk was not associated with risk-taking at a $p$ value of less than .20 , it was retained given our interest in environmental risk and its previously found effects on risk-taking and related competencies (Evans and English, 2002; Fergusson and Woodward, 2000; Scaramella et al., 1998). Further, past research has demonstrated the importance of including environmental risk as a co-predictor for regression analyses involving prenatal cocaine exposure (Bendersky et al., 1996, 2006; Bennett et al., 2013).

3.2. Prenatal cocaine exposure, biological sex, and a sex by cocaine interaction as predictors of adolescent risk-taking behavior

A hierarchical binary logistic regression was conducted to examine the relations of three predictors (biological sex, PCE, and a biological

\footnotetext{
${ }^{1}$ Separate correlation matrices for males and females indicated that the relation between alcohol exposure and risk-taking was moderated by sex such that only exposed females exhibited significant correlations with risk-taking. Correlations between prenatal cocaine and alcohol exposure were significant for both males and females.
} 
sex by PCE interaction) of risk-taking on the BART while controlling for early environmental risk and prenatal alcohol exposure. Biological sex and PCE were entered in step one to allow for an examination of their main effects, followed by the interaction term in step two. The covariates, environmental risk and prenatal alcohol exposure, were entered in step three.

The full model was statistically significant in differentiating between high and low risk-taking behavior on the BART $\left(\chi^{2}(5)=19.95\right.$, $p<.001)$. Table 2 presents the beta weights and significance levels for each variable for each of the three steps. In the full model, biological sex and the biological sex by PCE interaction were significant at $p<.05$ while the effect of prenatal exposure to alcohol approached significance $(p=.053)$. Both the main effects for PCE and early environmental risk were non-significant predictors of risk-taking. The odds ratio for biological sex indicated that when controlling for the other variables, males were 3.5 times more likely than females to be high risk-takers. Furthermore, the likelihood of scoring high on risk-taking increased as prenatal exposure to alcohol increased such that for each one-point increase of maternal alcohol consumption, the odds of scoring high on risk-taking doubled.

Although early environmental risk did not predict adolescent risktaking, additional analyses were conducted to explore possible interaction effects between environmental risk and both PCE and biological sex. Neither of these two interaction terms was significant when entered into step three of the model by themselves, together, or in combination with the sex by PCE interaction term from the original analysis. In each case the interaction terms involving environmental risk were not significant and, whenever included, the biological sex by PCE interaction term remained significant.

Additional analyses were conducted to explore the nature of the significant interaction between biological sex and PCE. Two follow-up regression analyses were conducted each using two steps. In step one, the sex by PCE interaction term was entered followed by the control variables in step two. The first follow-up analysis used exposed males as the reference group and found that the models from both steps were significant $\left(\chi^{2}(3)=8.68, p<.05\right)$ and $\left(\chi^{2}(5)=13.62, p<.01\right)$.

In step one there was a marginally significant effect $(p=.06)$ for exposed males such that they were more likely to score high on risktaking relative to unexposed males (see Fig. 1). This difference was eliminated after controlling for risk and alcohol exposure in step two (see Fig. 2). The second follow-up analysis used exposed females as the reference group and found that the models from both steps were significant $\left(\chi^{2}(3)=7.11, p<.05\right)$ and $\left(\chi^{2}(5)=12.85, p<.01\right)$. In step one, exposed females were not significantly different from exposed females (see Fig. 1); however, after controlling for risk and alcohol exposure in step two, there was a significant effect $(p<.05)$ such that exposed females were less likely to score high on risk-taking relative to unexposed females (see Fig. 2).

Table 2

Binary logistic regression predicting risk-taking at 16 years of age.

\begin{tabular}{llllllll}
\hline Model & Variables & \multicolumn{1}{l}{ B } & SE & $\operatorname{Exp}(\mathrm{B})$ & Sig. & Nagelkerke $R^{2}$ & $\Delta R^{2}$ \\
\hline 1 & & & & & & .10 & $.10^{*}$ \\
& Sex & 1.20 & 0.46 & 3.30 & $.009^{*}$ & & \\
$\mathbf{2}$ & Cocaine & 0.30 & 0.44 & 1.50 & .506 & & $.06^{*}$ \\
& & & & & & .16 & \\
& Sex & 1.26 & .49 & 3.51 & $.010^{*}$ & & $.08^{*}$ \\
& Cocaine & -.053 & .52 & 0.95 & .918 & & \\
& Sex $\times$ cocaine & -2.20 & 1.03 & 0.11 & $.032^{*}$ & & \\
& & & & & & .24 & \\
& Sex & 1.32 & 0.52 & 3.75 & $.010^{*}$ & & \\
& Cocaine & -1.09 & 0.80 & 0.34 & .173 & & \\
& Sex $\times$ cocaine & -2.67 & 1.15 & 0.07 & $.020^{*}$ & & \\
& Env. risk & -0.01 & 0.16 & 0.99 & .948 & & \\
& Alcohol & 0.66 & 0.34 & 1.94 & $.053^{\mathrm{t}}$ & & \\
& & & & & & & \\
\end{tabular}

Note. Env. risk, early environmental risk.

${ }^{*} p<.05,{ }^{t} p<.10$.

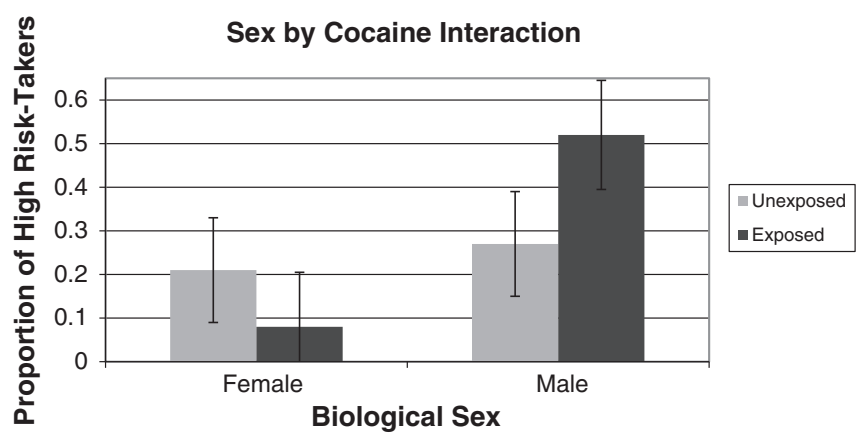

Fig. 1. Proportion of children classified as high risk-takers according to sex and prenatal cocaine exposure (expected value $=.25$ ) without covariates.

Additional analyses were conducted to directly test possible interaction effects between alcohol and cocaine. When entered into the model as the only interaction term, the alcohol by cocaine interaction was not significant. When added back into the model, the biological sex by cocaine interaction term from the original analysis significantly predicted adolescent risk-taking while the alcohol by cocaine interaction term remained non-significant.

Table 3 provides a summary of how each of the predictors and potential covariates were distributed according to high and low risktaking groups.

\section{Discussion}

The current study examined adolescent risk-taking behavior on the BART and its relation to PCE and biological sex, while controlling for early environmental risk and prenatal alcohol exposure. Adolescence is a particularly important period of development for two reasons: first, adolescence involves increasing independence and exposure to potentially risky activities (Steinberg, 2004); second, adolescence involves significant brain development (Casey et al., 2008). Accordingly, if the detrimental effects of PCE manifest during periods of rapid brain maturation (Liu and Lester, 2011), then it is important for research on the potential effects of PCE to explore the adolescent age group. For example, recent studies have demonstrated the long-term negative impact of PCE on increased adolescent substance use (Delaney-Black et al., 2011; Richardson et al., 2013).

A main finding from the present study was that males were 3.5 times more likely than females to be high risk-takers. This finding is consistent with evidence indicating that males tend to engage in greater realworld risk-taking than females in general (Byrnes et al., 1999; Harris et al., 2006). However, this general sex difference is not uniform across risk-taking domains and in some cases the difference seems to have narrowed over the past few decades of research (Byrnes et al., 1999; Abbott-Chapman et al., 2008). For the BART in particular, the effects of

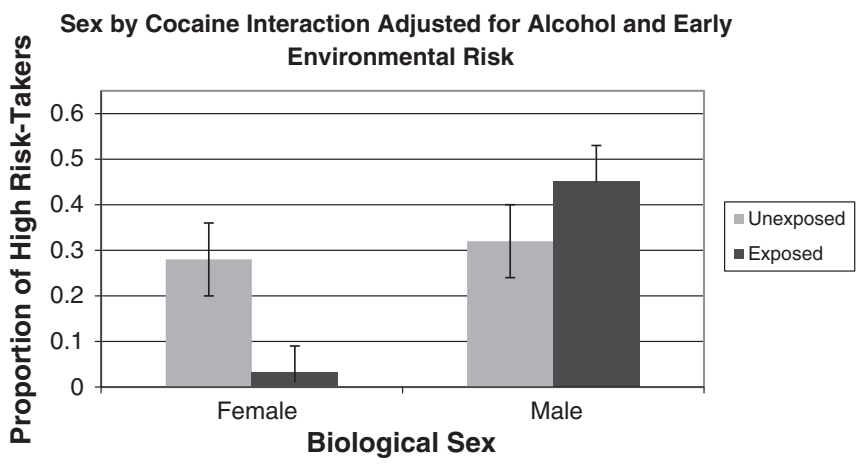

Fig. 2. Proportion of children classified as high risk-takers according to sex and prenatal cocaine exposure adjusted for prenatal alcohol exposure and early environmental risk (expected value $=.25$ ). 
Table 3

Distribution of risk-taking groups (high vs. low) by predictors and covariates.

\begin{tabular}{lllll}
\hline Predictor/covariate & $\begin{array}{l}\text { Statistical } \\
\text { test }\end{array}$ & Category & $\begin{array}{l}\text { Low risk } \\
(75 \%)\end{array}$ & $\begin{array}{l}\text { High risk } \\
(25 \%)\end{array}$ \\
\hline Gender & $X^{2}=7.10$ & Female & $84 \%$ & $16 \%$ \\
& $p<.01$ & Male & $62 \%$ & $38 \%$ \\
Prenatal cocaine & $X^{2}=.348$ & Unexposed & $76 \%$ & $24 \%$ \\
$\quad$ exposure & $p=n . s$. & Exposed & $71 \%$ & $29 \%$ \\
Gender $\times$ cocaine & $X^{2}=12.72$ & Male-exposed & $48 \%$ & $52 \%$ \\
interaction & $p<.01$ & Male-unexposed & $73 \%$ & $27 \%$ \\
& & Female-exposed & $92 \%$ & $8 \%$ \\
Early & & Female-unexposed & $79 \%$ & $21 \%$ \\
$\quad$ environmental & $p=n .5$. & $(\mathrm{CI})$ & 3.75 & 3.39 \\
$\quad$ risk & & & $(3.36-4.15)$ & $(2.70-4.08)$ \\
Prenatal alcohol & $\mathrm{F}=5.42$ & $\mathrm{M}$ & & \\
$\quad$ exposure & $p<.05$ & $(\mathrm{CI})$ & 0.54 & 1.03 \\
Prenatal cigarette & $\mathrm{F}=1.36$ & $\mathrm{M}$ & $(0.32-0.76)$ & $(0.67-1.39)$ \\
$\quad$ exposure & $p=n . s$. & $(\mathrm{CI})$ & 1.14 & 1.50 \\
Prenatal marijuana & $\mathrm{F}=0.00$ & $\mathrm{M}$ & $(0.82-1.46)$ & $(0.98-2.03)$ \\
$\quad$ exposure & $p=\mathrm{n} . \mathrm{s}$. & $(\mathrm{CI})$ & 0.24 & 0.23 \\
\hline
\end{tabular}

biological sex are more varied. Males have been shown to score higher than females in some (Lejuez et al., 2002; Lejuez et al., 2007) but not all studies (Aklin et al., 2005; Lejuez et al., 2003b). Moderators need to be considered in future research, as one study found sex differences on risk-taking were affected by stress such that stressed males showed increased risk-taking while stressed females showed increased riskavoidance (Lighthall et al., 2009). In our sample, sex differences varied with PCE.

Previous research has often found effects from PCE that are specific to males and typically greater than any effects for females (Lewis and Kestler, 2011). In particular, males have demonstrated significant effects of PCE for emotion regulation, aggression, externalizing problems, impulse control, motor inhibition, attention, and inhibitory control in research that spans development from infancy through preadolescence (Bandstra et al., 2001; Bendersky et al., 2003; Bennett et al., 2013; Carmody et al., 2011; Delaney-Black et al., 2004; Dennis et al., 2006; Kestler et al., 2011). In the present study, a sex by cocaine interaction was also found. However, the non-significant trend for exposed males to exhibit greater risk-taking was no longer observed after controlling for alcohol exposure. In contrast, females exhibited an unexpected finding as exposed females displayed less risk-taking than unexposed females after controlling for alcohol exposure.

Why prenatal exposure to alcohol would increase risk-avoidance for cocaine-exposed females is open to speculation. Previous research on prenatal alcohol exposure suggests that, if alcohol has any effect, it ought to compound the negative impact of PCE on developmental outcomes (Randall, 1992; Singer et al., 2000; Streissguth, 2011; cf. Sood et al., 2005). However, our pattern of results, in which females show greater risk-aversion and males show greater risk-taking, has been demonstrated for research in which participants were stressed prior to the risk-taking task (Lighthall et al., 2009; Preston et al., 2007). This research has suggested that there are biological sex differences in the way that stress-related hormones affect different regions of the brain that might explain the risk-aversion for females and risk seeking for males. Specifically, Lighthall et al. (2009) review evidence for the differential activation of emotional and visceral networks for females and dorsolateral and medial prefrontal regions for males. Whatever the precise neurobiological mechanisms involved, this research makes plausible the possibility that the effects of prenatal substance exposure on brain development could produce the unexpected risk-aversion behavior found for exposed females in the current study.

The final construct of interest in the present study concerned the influence of early environmental risk. Early environmental risk did not predict adolescent risk-taking behavior on the BART. A possible explanation for this finding is that factors other than early environmental risk are better predictors of adolescent risk-taking. Clearly, biological sex and the sex by PCE interaction in the current study are two such factors. Other factors may include ethnicity, inhibitory control, aggression, and sensation seeking (Hair et al., 2009; Zuckerman and Kuhlman, 2000). A second possibility to explain why early risk did not predict adolescent risk-taking is that other components of environmental risk are more strongly predictive of risk-taking than those included in the current study. The measure used in the current study included a number of important variables, but there were also variables that were not included (e.g., child maltreatment history, maternal mental health, and neighborhood violence exposure). While these other variables are clearly important, the current measure has been used previously to demonstrate the impact of environmental risk for other cognitive, emotional, and behavioral outcomes earlier in development (Bennett et al., 2008, 2013; Bendersky et al., 2006; Kestler et al., 2011). A third possibility to explain why early risk did not predict adolescent risktaking is that the negative effects of early environmental risk are mediated by other variables. Self-regulation abilities or neighborhood environment might mediate the effect of early risk on adolescent risktaking despite the absence of a direct effect between the two variables (Hayes, 2009). Alternatively, early environmental risk may indirectly influence adolescent risk-taking through a sequence of cascading effects in which early risk represents the first "domino" in the sequence.

The present study has several limitations. First, a measure of environmental risk specific to adolescence would provide a more comprehensive understanding of the potential impact of this variable on risktaking. Second, although the BART has shown evidence of external validity across a number of categories of risk-taking (Aklin et al., 2005; Fernie et al., 2010; Lejuez et al., 2003a,b) the current findings need to be extended using other "real-world" assessments of risk-taking. Third, this study was conducted with a low SES, urban, predominantly African-American sample and the findings may not generalize to other populations.

\section{Conclusion}

With increased independence and opportunity, the prevalence of risk-taking increases during adolescence and may set the stage for maladaptive behavior into adulthood. Therefore, the ability to identify children who are more likely to engage in risk-taking behaviors is a crucial aspect of any efforts aimed at prevention. The results from the current study indicate that PCE, prenatal alcohol exposure, and biological sex are related to the propensity for risk-taking behavior in adolescence. However, we do not know if the biological sex by PCE interaction effect is a new manifestation of long-term "sleeper" effects on adolescent brain maturation (Liu and Lester, 2011) or rather, a continuation of an impairment profile that has been demonstrated throughout childhood and preadolescence (Kestler et al., 2011). Further, the nature of the biological sex by PCE interaction changed after controlling for alcohol such that PCE females showed significantly greater risk-aversion relative to their unexposed peers. Future research will need to consider the possibility that, under certain conditions (e.g., conditions of stress, prenatal substance exposure, etc.), males and females may have different response profiles to risk-taking (enhancement vs. aversion) as well as differences in the most relevant predictors of those profiles.

\section{Conflict of interest statement}

No conflicts of interest to declare.

\section{Appendix A. Supplementary data}

Supplementary data to this article can be found online at http://dx. doi.org/10.1016/j.ntt.2013.12.003. 


\section{References}

Abbott-Chapman J, Denholm C, Wyld C. Gender differences in adolescent risk taking: Are they diminishing? An Australian intergenerational study. Youth Soc 2008;40: 131-54.

Ackerman JP, Riggins T, Black MM. A review of the effects of prenatal cocaine exposure among school-aged children. Pediatrics 2010;125:554-65.

Aklin WM, Lejuez CW, Zvolensky MJ, Kahler CW, Gwadz M. Evaluation of a behavioral measure of risk-taking propensity with inner-city adolescents. Behav Res Ther 2005;43:215-28.

Bada HS, Bann CM, Bauer CR, Shankaran S, Lester B, LaGasse L, et al. Preadolescent behavior problems after prenatal cocaine exposure: relationship between teacher and caretaker ratings (Maternal Lifestyle Study). Neurotoxicol Teratol 2011;33: 78-87.

Bandstra ES, Morrow CE, Anthony JC, Accornero VH, Fried PA. Longitudinal investigation of task persistence and sustained attention in children with prenatal cocaine exposure. Neurotoxicol Teratol 2001;23:545-59.

Bendersky M, Lewis M. Prenatal cocaine exposure and impulse control at two years. Ann N Y Acad Sci 1998;846:365-7.

Bendersky M, Lewis M. Prenatal cocaine exposure and neonatal condition. Infant Behav Dev 1999;22:353-66.

Bendersky M, Alessandri S, Gilbert P, Lewis M. Characteristics of pregnant substance abusers in two cities in the Northeast. Am J Drug Alcohol Abuse 1996;22: 349-62.

Bendersky M, Gambini G, Lastella A, Bennett DS, Lewis M. Inhibitory motor control at five years as a function of prenatal cocaine exposure. J Dev Behav Pediatr 2003;24: 345-51.

Bendersky M, Bennett DS, Lewis M. Aggression at age five as a function of prenatal exposure to cocaine, gender, and environmental risk. J Pediatr Psychol 2006;31:71-84.

Bennett DS, Bendersky M, Lewis M. Preadolescent health risk behavior as a function of prenatal cocaine exposure and gender. Dev Behav Pediatr 2007;28:467-72.

Bennett DS, Bendersky M, Lewis M. Children's cognitive ability from 4 to 9 years old as a function of prenatal cocaine exposure, environmental risk, and maternal verbal intelligence. Dev Psychol 2008;44:919-28.

Bennett DS, Marini VA, Berzenski SR, Carmody DP, Lewis M. Externalizing problems in late childhood as a function of prenatal cocaine exposure and environmental risk. J Pediatr Psychol 2013;38:296-308.

Bridgett DJ, Mayes LC. Development of inhibitory control among prenatally cocaine exposed and non-cocaine exposed youths from late childhood to early adolescence: the effect of gender and risk and subsequent aggressive behavior. Neurotoxicol Teratol 2011;33:47-60.

Burchinal M, Roberts J, Hooper S, Zeisel S. Cumulative risk and early cognitive development: a comparison of statistical risk models. Dev Psychol 2000;36:793-807.

Byrnes JP, Miller DC, Schafer WD. Gender differences in risk taking: a meta-analysis. Psychol Bull 1999;125:367-83.

Campbell SB, Shaw DS, Gilliom M. Early externalizing behavior problems: toddlers and preschoolers at risk for later maladjustment. Dev Psychopathol 2000;12:467-88.

Carmody DP, Bennett DS, Lewis M. The effects of prenatal cocaine exposure and gender on inhibitory control and attention. Neurotoxicol Teratol 2011;33:61-8.

Casey BJ, Getz S, Galvan A. The adolescent brain. Dev Rev 2008;28:62-77.

CDC. Youth risk behavior surveillance system. Atlanta, GA: U.S. Department of Health and Human Services; 2011.

Crowley MJ, Wu J, Crutcher C, Bailey CA, Lejuez CW, Mayes LC. Risk-taking and the feedback negativity response to loss among at-risk adolescents. Dev Neurosci 2009;31:137-48.

Delaney-Black V, Covington C, Nordstron B, Ager J, Janisse J, Hannigan JH, et al. Prenatal cocaine: quantity of exposure and gender moderation. Dev Behav Pediatr 2004;25: 254-63.

Delaney-Black V, Chiodo LM, Hannigan JH, Greenwald MK, Janisse J, Patterson G, et al. Prenatal and postnatal cocaine exposure predict teen cocaine use. Neurotoxicol Teratol 2011;33:110-9.

Dennis T, Bendersky M, Ramsay D, Lewis M. Reactivity and regulation in children prenatally exposed to cocaine. Dev Psychol 2006;42:688-97.

Evans GW, English K. The environment of poverty: multiple stressor exposure, psychophysiological stress, and socioemotional adjustment. Child Dev 2002;73: 1238-48.

Fergusson DM, Woodward LJ. Educational, psychosocial, and sexual outcomes of girls with conduct problems in early adolescence. J Child Psychol Psychiatry 2000;41: 779-92.

Fernie G, Cole JC, Goudie AJ, Field M. Risk-taking but not response inhibition or delay discounting predict alcohol consumption in social drinkers. Drug Alcohol Depend 2010;112:54-61.

Hair EC, Park MJ, Ling TJ, Moore KA. Risky behavior in late adolescence: co-occurrence, predictors, and consequences. J Adolesc Health 2009;45:253-61.

Harris CR, Jenkins M, Glaser D. Gender differences in risk assessment: why do women take fewer risks than men? Judgm Decis Making 2006;1:48-63.

Hayes AF. Beyond Baron and Kenny: statistical mediation analysis in the new millennium. Commun Monogr 2009;76:408-20.

Hoerger M, Quirk SW, Weed NC. Development and validation of the delaying gratification inventory. Psychol Assess 2011;23:725-38
Jessor R. Risk behavior in adolescence: a psychological framework for understanding and action. J Adolesc Health 1991;12:597-605.

Kestler L, Bennett DS, Carmody DP, Lewis M. Gender-dependent effects of cocaine exposure. In: Lewis M, Kestler L, editors. Gender differences in prenatal substance exposure. APA; 2011. p. 11-29.

Lebel C, Warner T, Colby J, Soderberg L, Roussotte F, Behnke M, et al. White matter microstructure abnormalities and executive function in adolescents with prenatal cocaine exposure. Psychiatry Res 2013;213:161-8.

Leigh BC. Peril, chance, and adventure: concepts of risk, alcohol use and risky behavior in young adults. Addiction 1999;94:371-83.

Lejuez CW, Read JP, Kahler CW, Richards JB, Ramsey SE, Stuart GL, et al. Evaluation of a behavioral measure of risk taking: the balloon analogue risk task (BART). J Exp Psychol Appl 2002;8:75-84.

Lejuez CW, Aklin WM, Jones HA, Richards JB, Strong DR, Kahler CW, et al. The Balloon Analogue Risk Task (BART) differentiates smokers and nonsmokers. Exp Clin Psychopharmacol 2003a; 11:26-33.

Lejuez CW, Aklin WM, Zvolensky MJ, Pedulla CM. Evaluation of the Balloon Analogue Risk Task (BART) as a predictor of adolescent real-world risk-taking behaviors. J Adolesc 2003b;26:475-9.

Lejuez CW, Aklin W, Daughters S. Reliability and validity of the youth version of the Balloon Analogue Risk Task (BART-Y) in the assessment of risk-taking behavior among inner-city adolescents. J Clin Child Adolesc Psychol 2007:36:106-11.

Lewis M, Kestler L. Gender differences in prenatal substance exposure. Washington, DC: APA; 2011.

Lighthall NR, Mather M, Gorlick MA. Acute stress increases sex differences in risk seeking in the balloon analogue risk task. PLoS One 2009;4:1-6.

Liu J, Lester BM. Reconceptualizing in a dual-system model the effects of prenatal cocaine exposure on adolescent development: a short review. Int J Dev Neurosci 2011;29:803-9.

Masten AS, Coatsworth JD, Neemann J, Gest SD, Tellegen A, Garmezy N. The structure and coherence of competence from childhood through adolescence. Child Dev 1995;66: 1635-59.

Mayes LC, Cicchetti D, Acharyya S, Zhang H. Developmental trajectories of cocaine-and-other-drug-exposed and non-cocaine-exposed children. J Dev Behav Pediatr 2003;24:323-35.

Mischel W, Ayduk O, Berman MG, Casey BJ, Gotlib IH, Jonides J, et al. 'Willpower' over the life span: decomposing self-regulation. Soc Cogn Affect Neurosci 2011;6:252-6.

Preston SD, Buchanan TW, Stansfield RBS, Bechara A. Effects of anticipatory stress on decision making in a gambling task. Behav Neurosci 2007;141:257-63.

Randall T. Cocaine, alcohol mix in body to form even longer-lasting more lethal drug. JAMA 1992;270:1581-6.

Raver CC. Placing emotional self-regulation in sociocultural and socioeconomic contexts. Child Dev 2004;75:346-53.

Richardson GA, Goldschmidt L, Willford J. Continued effects of prenatal cocaine use: preschool development. Neurotoxicol Teratol 2009;31:325-33.

Richardson GA, Goldschmidt L, Leech S, Willford J. Prenatal cocaine exposure: effects on mother- and teacher-rated behavior problems and growth in school-age children. Neurotoxicol Teratol 2011;33:69-77.

Rubin DB. Multiple imputation for nonresponse in surveys. New York: Wiley; 1987.

Richardson GA, Larkby C, Goldschmidt L, Day NL. Adolescent initiation of drug use: effects of prenatal cocaine exposure. J Am Acad Child Adolesc Psychiatry 2013;52:37-46.

Sameroff A, Seifer R, Zax M, Barocas R. Early indicators of developmental risk: Rochester longitudinal study. Schizophr Bull 1987a;13:383-94.

Sameroff A, Seifer R, Zax M, Barocas R, Greenspan S. Intelligence quotient scores of 4-year-old children: social-environmental risk factors. Pediatrics 1987b;79:343-50.

Scaramella LV, Conger RD, Simons RL, Witbeck L. Predicting risk for pregnancy by late adolescence: a social contextual perspective. Dev Psychol 1998;34:1233-45.

Schafer JL, Graham JW. Missing data: our view of the state of the art. Psychol Methods 2002;7:147-77.

Sektnan M, McClelland MM, Acock A, Morrison FJ. Relations between early family risk, children's behavioral regulation, and academic achievement. Early Child Res Q 2010;25:464-79.

Sheinkopf SJ, Lester BM, Sanes JN, Eliassen JC, Hutchison ER, Seifer R, et al. Functional MRI and response inhibition in children exposed to cocaine in utero. Preliminary finding. Dev Neurosci 2009;31:159-66.

Singer LT, Arendt R, Minnes S, Farkas K, Salvator A. Neurobehavioral outcomes of cocaine-exposed infants. Neurotoxicol Teratol 2000;22:653-66.

Sood BG, Bailey BN, Covington C, Sokol RJ, Ager J, Janisse J, et al. Gender and alcohol moderate caregiver reported child behavior after prenatal cocaine. Neurotoxico Teratol 2005;27:191-201.

Steinberg L. Risk taking in adolescence: what changes and why? Ann N Y Acad Sci 2004;1021:51-8

Streissguth AP. Sex differences in prenatal alcohol abuse in humans. In: Lewis M, Kestler L editors. Gender differences in prenatal substance exposure. APA; 2011. p. 11-29.

Warner TD, Behnke M, Eyler FD, Padgett K, Leonard C, Hou W, et al. Diffusion tensor imaging of frontal white matter and executive functioning in cocaine-exposed children. Pediatrics 2006;118:2014-24.

White TL, Lejuez CW, de Wit H. Test-retest characteristics of the balloon analogue risk task (BART). Exp Clin Psychopharmacol 2008;16:565-70.

Zuckerman M, Kuhlman DM. Personality and risk-taking: common biosocial factors. J Personal 2000;68:999-1029. 